\title{
Missing and Murdered
}

Grant Spotted Bull

spobu149@gmail.com

\begin{abstract}
Spotted Bull's series of paintings depict graphically, the experiences of First Nations women who have suffered from systemic violence and have been murdered. He states that the spirits of the missing and murdered women will roam, until they are bought home to rest. In the following video, Spotted Bull describes issues faced by Aboriginal peoples through his art in the Medicine Wheel Series and in stories represented in the Missing and Murdered Women and Girls Series. https://ualberta.aviaryplatform.com/r/dr2p55f832
\end{abstract}

Keywords: Colonization, structural and systemic violence, oppression 